\title{
Alginate oligosaccharide attenuates a2,6- sialylation modification to inhibit prostate cancer cell growth via the Hippo/YAP pathway
}

\author{
Yang Han ${ }^{1}$, Lin Zhang ${ }^{1}$, Xiao Yu ${ }^{2}$, Shidan Wang ${ }^{1}$, Chunyan $X u^{1}$, Heng Yin ${ }^{3}$ and Shujing Wan
}

\section{Abstract}

Chitosan oligosaccharides have been reported to inhibit various tumors. However, the ter-soluble marine plant oligosaccharide alginate oligosaccharide (AOS) has only rarely been reported to $\mathrm{m}$ e anti-cancer effects. Moreover, the inhibitory effect of AOS on prostate cancer and the underlying moleculan. remain unknown. This study shows that AOS inhibited cell growth, which was consistent with the attenua n of a2,6-sialylation modification. Furthermore, AOS inhibited ST6Gal-1 promoter activity and thus affectranschptional processes. In addition, AOS could activate the Hippo/YAP pathway and block the recruitment of bolh tne_oactivator YAP and c-Jun. Furthermore, YAP interacted with the transcription factor c-Jun and regulated the trar scriptional activity of the downstream target ST6Gal-1 gene. Consistent with in vitro data, AOS suppresse a tin morigenicity of prostate cancer cells via the Hippo/ YAP pathway in vivo. In summary, these data indicate that is slo $s$ the proliferation of prostate cancer and provides a basis for the healthy function of kelp in traditiona/cognit.

\section{Introduction}

Prostate cancer is a significant publi disease across the world and the most common solid imor dingnosed in males in the United States. Further 'e, it is a severe disease with high incidence $r$ and tatality ${ }^{1}$. Prostate cancers are typically characterize $\mathrm{d} \mathrm{D}_{\mathrm{N}} \mathrm{o}$ androgen levels and during initial stag prost te cancer responds to hormonal intervent th rmanies. However, with the emergence of undro, n-incependence, the tumor becomes mor dvancea, which leads to castrationresistant proutate nncers. This is a lethal form of

Correcnonden, Hens, Yin (yinheng@dicp.ac.cn) or Shujing Wang

(vang, jing@a -du.edu.cn)

part 3 fochemistry and Molecular Biology, College of Basic Medical Sc. es, Instrute of Glycobiology, Dalian Medical University, Dalian, Liaoning, China

${ }^{2}$ Depart, nent of Pathology, College of Basic Medical Sciences, Dalian Medical University, Dalian, Liaoning, China

Full list of author information is available at the end of the article.

Edited by A. Stephanou prostate cancer, which has no effective treatment to date ${ }^{2}$. Currently, the standard therapies for castration-resistant prostate cancer include hormone therapy, chemotherapy, and radiation. However, such treatments cannot inhibit tumor metastasis and pose high toxicity to normal tissues in patients ${ }^{3}$. Therefore, effective drugs for the treatment of prostate cancer are a top priority. Furthermore, despite tremendous advances in surgery, chemotherapy, and drug therapy, the incidence of prostate cancer is still increasing due to a tendency of recurrence and metastasis ${ }^{4}$. Therefore, identifying the molecular mechanism underlying the process of prostate cancer development will be helpful for both diagnosis and treatment.

Alginate oligosaccharide (AOS) consists of $\beta$-D-mannuronic acid (mannuronic acid) and $\alpha$-L-guluronic acid (guluronic acid) linked via 1,4-glycosidic bonds. It is a water-soluble functional oligomer ${ }^{5}$, and is derived from brown algae ${ }^{6}$. Furthermore, it has been regarded as a nontoxic and biodegradable polymer, and has a bright

\section{(c) The Author(s) 2019}

(c) Open Access This article is licensed under a Creative Commons Attribution 4.0 International License, which permits use, sharing, adaptation, distribution and reproduction cc) in any medium or format, as long as you give appropriate credit to the original author(s) and the source, provide a link to the Creative Commons license, and indicate if changes were made. The images or other third party material in this article are included in the article's Creative Commons license, unless indicated otherwise in a credit line to the material. If material is not included in the article's Creative Commons license and your intended use is not permitted by statutory regulation or exceeds the permitted use, you will need to obtain permission directly from the copyright holder. To view a copy of this license, visit http://creativecommons.org/licenses/by/4.0/. 
prospect for biomedical applications ${ }^{7}$. The antioxidant property of AOS has received significant attention ${ }^{5,8}$. This type of oligosaccharide possesses additional beneficial characteristics such as anti-inflammatory activity ${ }^{5}$ and bacteriostatic function ${ }^{9}$. The most unique feature is its antineoplastic activity ${ }^{10,11}$. Little is known about the relationship between AOS and the development of prostate cancer. Therefore, this study investigated whether AOS could impact the growth and proliferation of prostate cancer cells.

Glycosylation plays an essential role in many biological processes such as immune surveillance and tumor progression $^{12,13}$. Sialic acid (SA) is a derivative of the ninecarbon monosaccharide family, in which terminal monosaccharides are attached to a glycan chain ${ }^{14,15}$. Sialylation is closely associated with many cellular functions, such as cell adhesion, signal recognition, and protein stability ${ }^{16,17}$. The sialyltransferase (ST) family is a group of sialylation synthases, consisting of 20 members that have been divided into $\beta$-galactoside $\alpha 2,3$-sialyltransferases (ST3GalI-VI), $\beta$-galactoside $\alpha 2,6$-sialyltransferases (ST6Gal-I and II), GalNAc $\alpha 2,6$-sialyltransferases (ST6Gal-NAcI-VI), and $\alpha 2,8$-sialyltransferases (ST8SIAI-VI) families ${ }^{18}$. The sialyltransferase that catalyzes $\alpha 2,6$-linked SA, especially ST6Gal1 , is the main sialyltransferase among these. $\beta$-galactoside $\alpha 2,6$-sialyltransferase 1 (ST6Gal-1) adds an $\alpha 2,6$-linked of to the N-glycans of specific receptors ${ }^{19}$. High expre $\left.n\right) f$ ST6Gal-1 has been reported to be related to nalig. tt tumor invasion and metastasis ${ }^{20,21}$. Previous dies hav reported that ST6Gal-1 is upregulated in even cancer types, including many colon carcinom as ${ }^{19}$, liver ca $\mathrm{Cer}^{22}$, and prostate cancer ${ }^{23}$. However, the tricate relationship between AOS and ST6Gal-1 and the lecular mechanisms underlying prostate cance nrogression still remain poorly understood.

This study further exp $\mathrm{d}$ a cr tical role that AOS may play in the modulatio of $\mathrm{p}$ ctate cancer cell growth both in vitro and in ivo. his sudy further investigated whether AOS ibits th growth and proliferation of prostate cancur ce. through the sialylation of N-glycans, mediated by ST6Gar 1 on the cell surface. The results showea at $4 O S$ had a significant anti-tumor effect and inhilited expressions of ST6Gal-1 both in mRNA 1 vels nd pry iein levels. Furthermore, the apoptosis rates o. 1ucun overexpressing cells increased significantly whe ompared to the control group in both presence and absence of AOS. In addition, in pathway perspective, AOS triggered the activation of the Hippo/YAP signaling pathway. In summary, the results of this study indicate that AOS could modulate the expression of ST6Gal-1 via the Hippo/YAP pathway and play a fundamental role in prostate cancer cell growth and proliferation.

\section{Results}

Anti-proliferation effects of AOS in human prostate cancer cells

The chemical structure of AOS is shown in Fig. 1a. Previous experiments have shown that AOS has no apparent cytotoxicity to human normal cells (S pplementary Fig. S1). To examine the effects of AOS on cancer cell growth, human prostate cancer DL and PC-3 cell lines were treated with various concentrati of AOS $(0,50,100,500$, and $1000 \mu \mathrm{g} / \mathrm{ml}) / \mathrm{co} \quad \mathrm{h}$, at $\mathrm{d}$ then viable cells were determined via $C C K-8$ ass Ao shown in Fig. 1b, AOS treatment inhibite DU145 an $\mathrm{AC}-3$ cell proliferation. Medication with lo ar concentrations of AOS $(100$ and $500 \mu \mathrm{g} / \mathrm{ml})$ ro ted or owth inhibition without cell death after $24 \mathrm{n}$ of atment. In addition, a colony-formation ass $y<$ used 2.o verify cell proliferation changes. AOS treatmo also decreased DU145 and PC-3 cell colon tor ation (E/g. 1c). To study the possible function of $A$;ulating apoptosis in prostate cancer cells, Ann $n$ V-FITC/PI staining was used. As shown in $1 \mathrm{~d}$, the apoptosis rates of prostate cancer cells increase $4 \mathrm{~h}$, the presence of AOS. Accordingly, AOS triggered cell cycle arrest during the S phase (Fig. 1e). No the effects of apoptotic-related proteins were exam led via Western blot analysis. Exposure to different centrations of AOS resulted in increased levels of cleaved PARP, cleaved caspase-9, Bax protein and an inhibition of the Bcl-2 protein level (Fig. 1f). These results indicate that AOS could suppress the proliferation ability of DU145 and PC-3 cells.

\section{AOS treatment suppressed DU145 and PC-3 cell migration and invasion ability in vitro}

To investigate the effects of AOS on the migration and invasion abilities of prostate cancer cells, wound healing and transwell assays were used. The changes in migration ability were studied before and after AOS treatment in both DU145 and PC-3 cells. The results showed that drug treatment inhibited the migration ability of DU145 and PC-3 cells (Fig. 2a, b). Furthermore, transwell migration assays were conducted to analyze the migration ability of DU145 and PC-3 cells, and results were identical as those of the wound-healing assay (Fig. 2c). Moreover, Matrigelinvasion assay was also conducted and it showed that after AOS treatment, invasion ability of prostate cancer cells was suppressed (Fig. 2d). Moreover, the effects of migration-related proteins were examined. The results indicated that different concentrations of AOS contributed to MMP2 and MMP9 downregulation in prostate cancer cells (Fig. 2e). In summary, these results demonstrated that AOS treatment suppressed the migration and invasion abilities of both DU145 and PC-3 cells. 


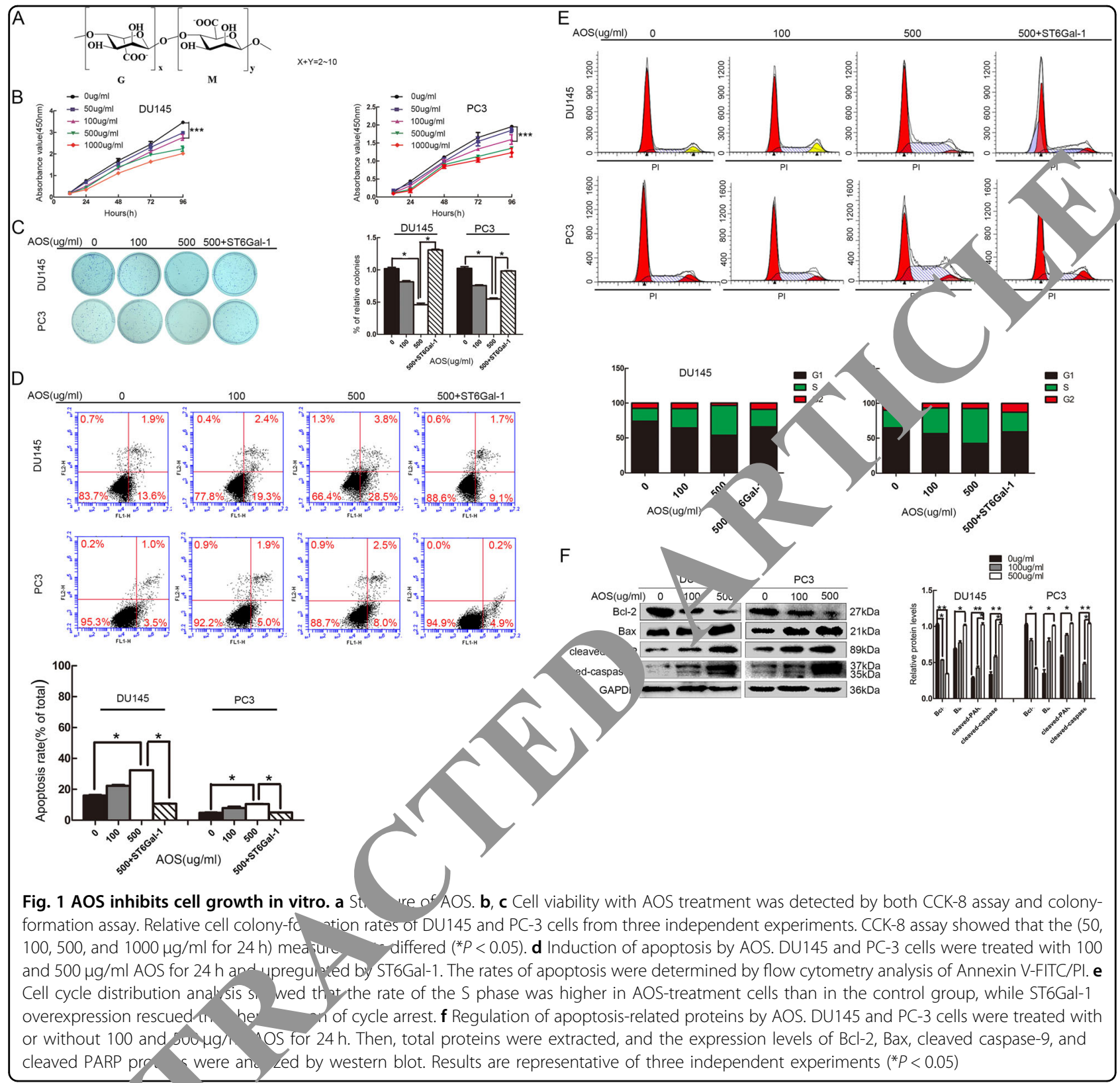

Effect 0.0 , on the expression profile of sialyltransferase gep and vinregulation of ST6Gal-1 expression in uma prost ce cancer cells

ceferestion of sialyltr. ferase genes in the human prostate cancer cell line DU145, the mRNA expression levels of sialyltransferase genes were examined. As shown in Fig. 3a-d, the transcription levels of ST3GAL3, ST6GAL1, ST6GALNAC5, and ST8SIA4 were different after treatment with AOS. The mRNA levels of ST6GAL1, ST6GALNAC5, and ST8SIA4 were significantly decreased. Higher expression levels of ST6GAL1 were observed and the difference in the role of AOS was obvious (2.93-fold), whereas
ST3GAL3, ST6GALNAC5, and ST8SIA4 expression levels were not high. In summary, these results implied that the ST6GAL1 gene was highly expressed in prostate cancer cells and the effect of AOS on ST6GAL1 differed significantly.

Previous studies have shown that ST6Gal-1 plays a fundamental role in growth, migration, and invasion of prostate cancer PC-3 and DU145 cells ${ }^{23}$. The corresponding assays associated with the role of ST6Gal-1 in tumor growth are shown in Supplementary Materials. AOS exerts a clear impact on ST6Gal-1 in the human prostate cancer cell line DU145 (Fig. 3b). Therefore, the expression of sialyltransferase ST6Gal-1 encoded by the 


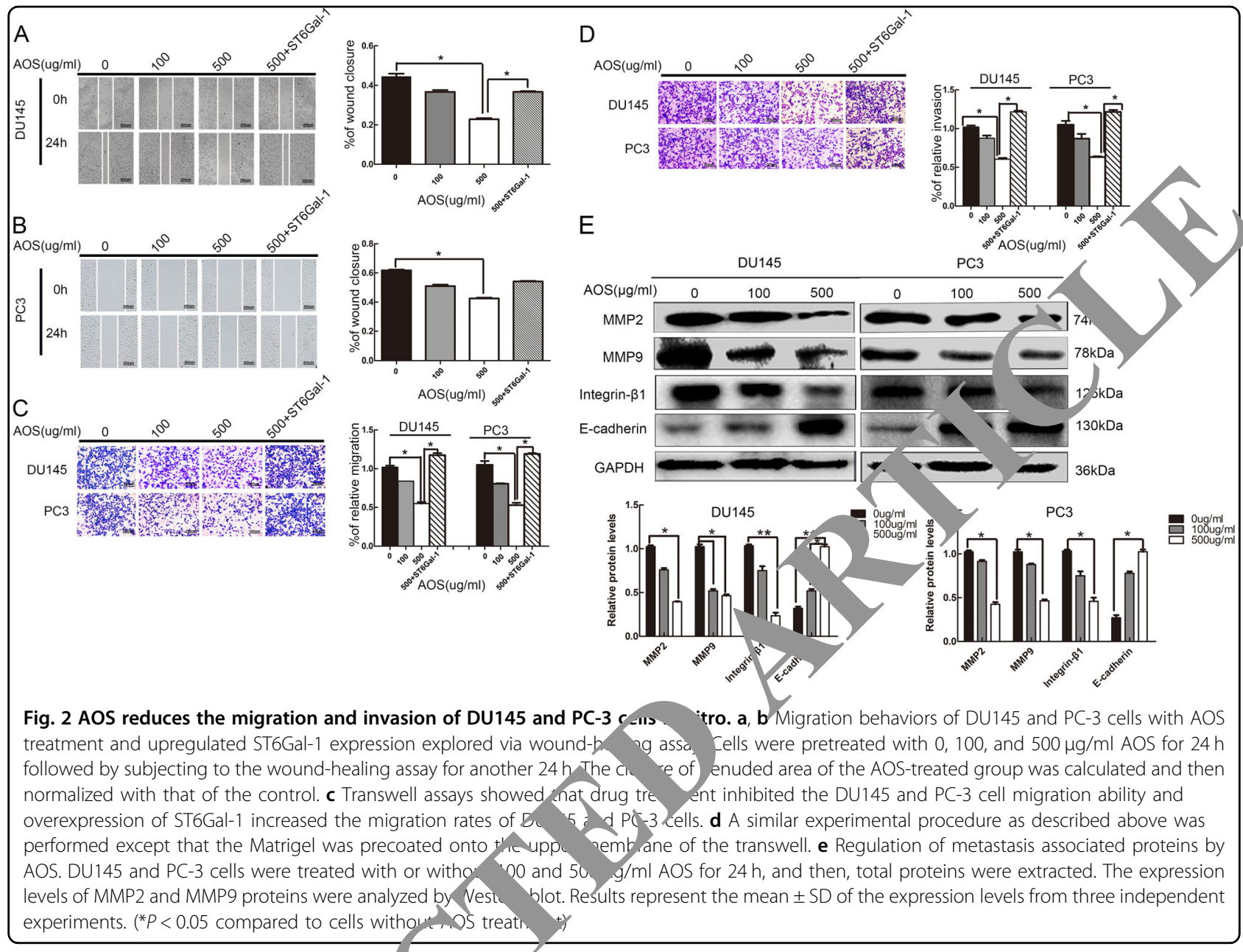

ST6GAL1 gene was evaluated to lincidate the suppression function of AOS to ST6Gal-1. A. Si, in Fig. 3e, f, AOS decreased the relative VA levels of ST6Gal-1. Furthermore, western b- an lysis showed that ST6Gal-1 protein levels de Geasi correspondingly (Fig. 3g, h). Accordingly, S , lectin bly indicated that $\alpha 2$,6-linked SA was decreasea afte. OS treatment (Fig. 3i). Furthermore, ST6Gal-1/ overexpres, on rescued the reduction of SNA lectin s. is $\alpha$ cdused by AOS (Fig. 3i). Therefore, these dat : ndica tha ST6Gal-1 might be a targeting molecule, hic cont buted to AOS-suppressed proliferation, n. atum, and invasion of DU145 and PC-3 cells.

\section{Activation of the Hippo/YAP signaling pathway by AOS}

It has been reported that the Hippo/YAP signaling pathway plays a central role in the progression of tumorigenicity ${ }^{24}$. Therefore, this study investigated whether this pathway was involved in AOS-mediated prostate cancer cell proliferation, migration, and invasion. The expression levels of Hippo family members, including a panel of kinases (MST1/2 and LATS1) and adaptor proteins (SAV1 and MOB1), and downstream transcriptional factor YAP were investigated by Western blot analysis. As shown in Fig. 4a, b, relatively high levels of MST1/2, LATS1, SAV1, and MOB1 were found in AOStreated cells. However, expression of the oncogene YAP was decreased in DU145 and PC-3 cells in response to AOS treatment. These observations clearly indicate that AOS could promote the activation of the Hippo/YAP pathway in prostate cancer cells. Additionally, immunofluorescence experiment showed increased expression and accumulation of YAP in the cytoplasm, i.e., the promotion of YAP transfer from the nucleus to the cytoplasm in response to AOS treatment (Fig. 4c, d). In summary, these findings suggest that AOS might be associated with the Hippo/YAP pathway and activated the Hippo signaling pathway in human prostate cancer cells.

\section{Overexpression of ST6Gal-1 rescues the activation of the Hippo/YAP signaling pathway in DU145 and PC-3 cells}

To further verify that AOS may affect the development of prostate cancer by regulating the expression of ST6Gal-1, 


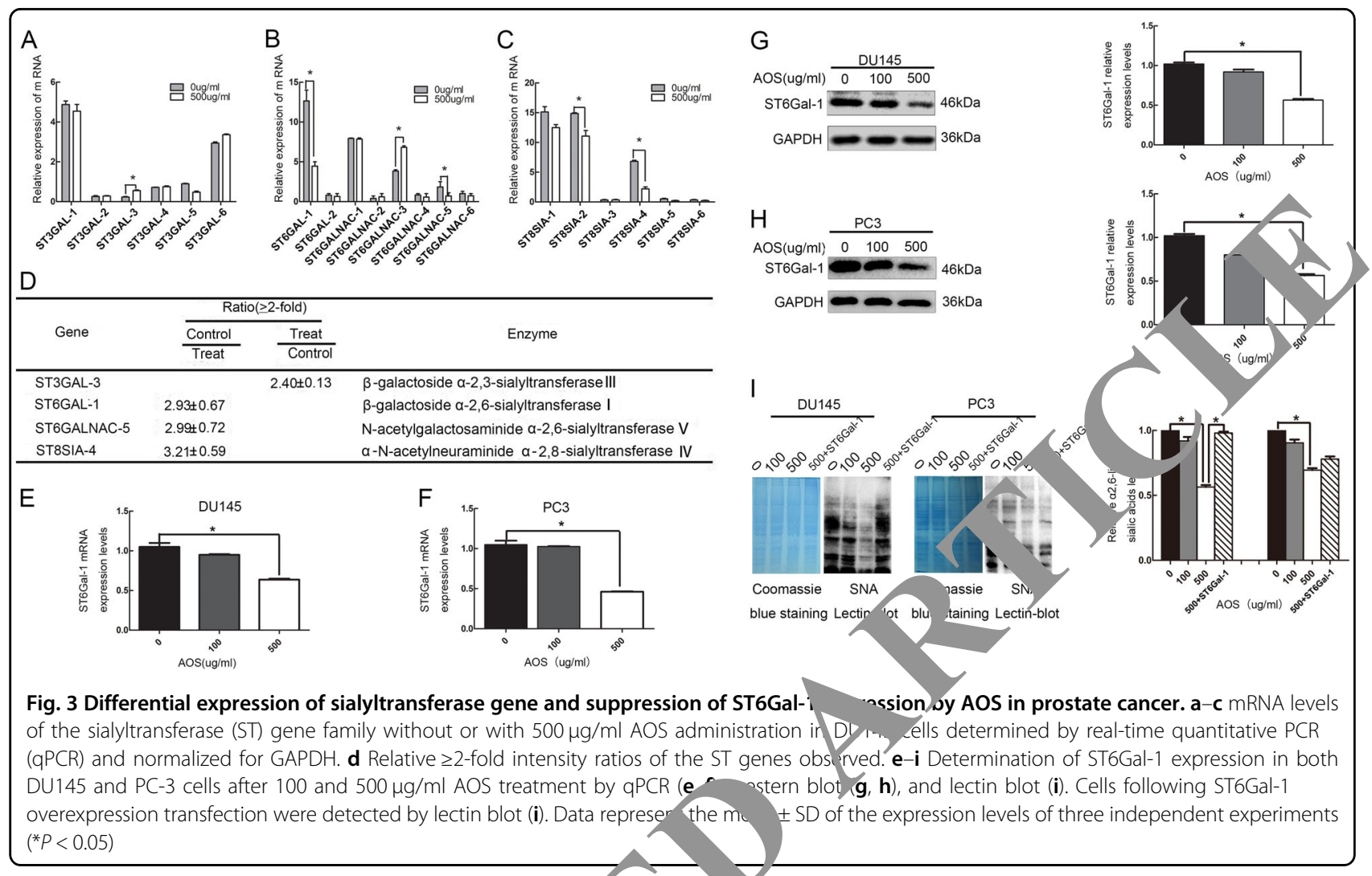

cells that had been treated with $500 \mu \mathrm{g} / \mathrm{ml}$ s.2S transfected with ST6Gal-1 overexpression y rs. Reir. troduction of ST6Gal-1 in AOS-induced reals sis Gcantly modified the levels of Hippo signali ig-related $\mathrm{p}$, oteins expression. Clonogenic capacity an apoptotic ability, migration, and invasion abilities were 1 red ty ST6Gal-1 overexpression (Figs. 1c-e and $-\mathrm{d}$ ). In addition, AOSinduced S-phase arrest was a'so nuated (Fig. 1f). Immunofluorescence rec shoned that ST6Gal-1 overexpression rescued th tran for of YAP, which was conditioned by AOS, winch scated from the nucleus to the cytoplasm and $\mathrm{k}$ to the acleus (Fig. 4c, d). Moreover, the level of piosp. vlated YAP returned to the original level com pared to Ao - -mediated groups (Fig. 5a, b). YAP overex $\mathrm{si}$ stimulated the expression of ST6Gal-1 (Fig. $5 \mathrm{c}-\mathrm{T}$ Th outcomes indicate that upregulation of C T6G $1-1 \mathrm{mi}$ ont rescue the proliferation, migration, and 1. Dilities of both DU145 and PC-3 cells by rest ing the activation of the Hippo/YAP pathway facilitated by AOS.

\section{Synergistic interaction between YAP and c-Jun plays a role in the AOS-mediated inhibitory effect on ST6Gal-1 gene expression}

Bioinformatics predicted that the c-Jun transcription factor is located upstream of the ST6Gal-1 promoter and upregulated ST6Gal-1 gene expression. This study evaluated the effect of AOS on transcriptional activity of the ST6Gal-1 promoter. The results of the dual-luciferase reporter gene assay indicated the inhibition of AOS to ST6Gal-1 promoter activity and the core functional area was located at nucleotides $-308 /+1$ upstream of the ST6Gal-1 promoter (Fig. 6a). Furthermore, Fig. 6b shows a schematic diagram of the c-Jun response element located at nucleotides $-308 /+1$ upstream of the ST6Gal1 promoter region. Examination of the ST6Gal-1 promoter region found one putative c-Jun-binding site. Individual mutation of this putative c-Jun-binding site indicated that the transcription factor c-Jun was involved in the regulation of ST6Gal-1 promoter activity (Fig. 6c). Furthermore, upregulated ST6Gal-1 was detected by antic-Jun antibody chromatin immunoprecipitation (CHIP) assay. As depicted in Fig. 6d, reduction of c-Jun interaction at the c-Jun response element located at (nucleotides $-308 /+1$ ) upstream of the ST6Gal-1 promoter in AOStreated cells was concentration dependent. These studies indicated that AOS could decrease the recruitment of cJun into the upstream response region of the ST6Gal-1 promoter in prostate cancer cells.

This study focused on validating the associations between YAP and c-Jun via co-immunoprecipitation (CoIP) (Fig. 6g). In addition, cells were treated with 0, 100, and $500 \mu \mathrm{g} / \mathrm{ml}$ AOS for $24 \mathrm{~h}$ and YAP was upregulated by transfection with pcDNA3.1/YAP plasmid. Relative 


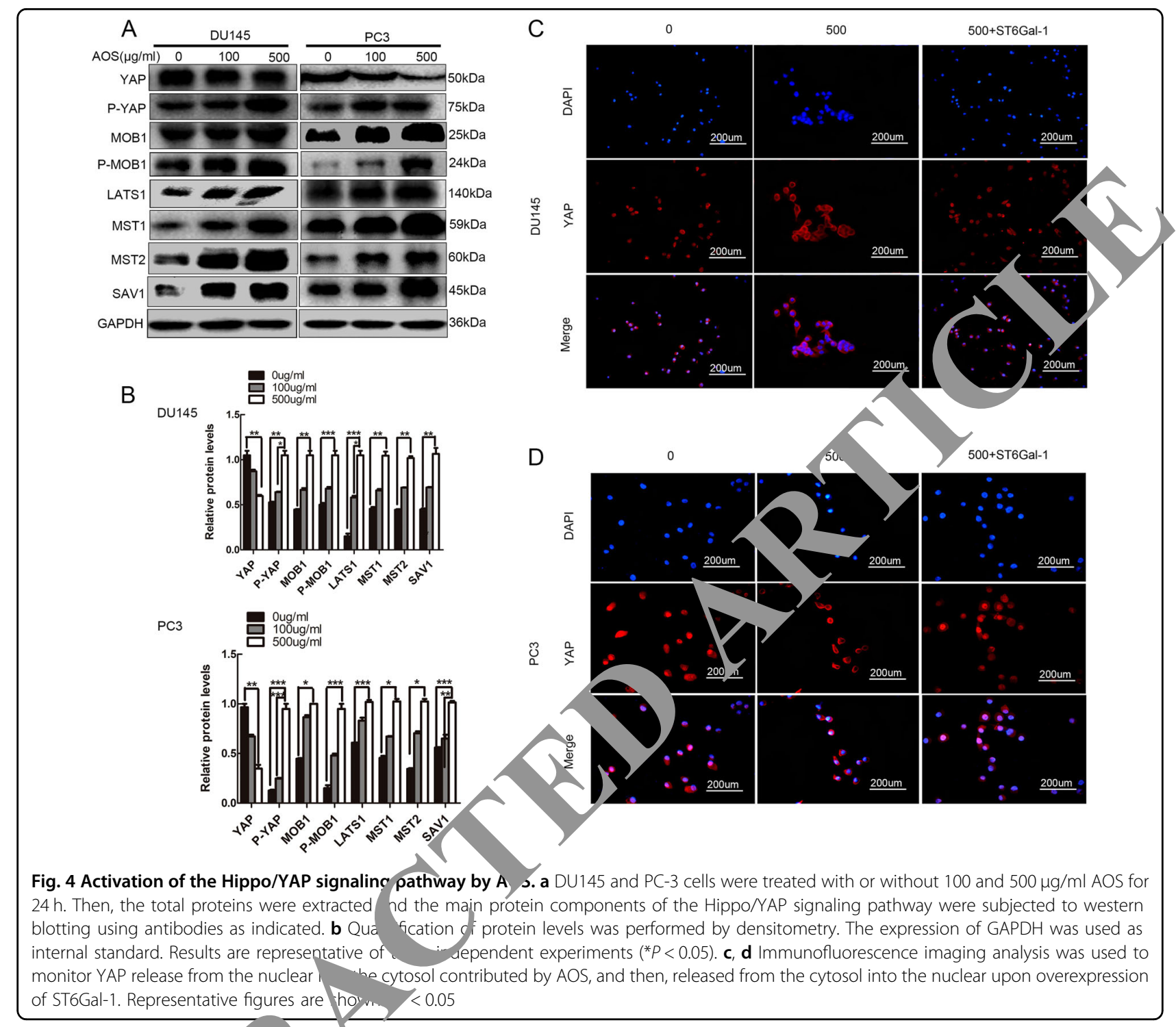

protein levels of c,un the results are 'ustratea $A$ Fig. 6e. Furthermore, colocation of HAP a c-Jun proteins inside the prostate cancer crils was obs, ived by cell immunofluorescence. Both $\mathrm{y}$ a d c-'un were mainly localized in the nucleus $(\mathrm{Fi}-\mathrm{G})$. I $\mathrm{Im}$ nary, these results validated the interac+ on tween YAP and c-Jun played a major role in the A -muated inhibitory effect on ST6Gal-1 gene exp ion in prostate cancer cells.

\section{AOS treatment attenuates prostate cancer cell} tumorigenicity in nude mice via the Hippo/YAP pathway in vivo

To investigate the effect of AOS on tumor development, a subcutaneous engraftment assay was conducted in nude mice and AOS was administered consecutively for $21 \mathrm{~d}$ by intraperitoneal injection once per day at doses of 0.5 and
$2.5 \mathrm{mg} / \mathrm{kg}$. The mice were then sacrificed. As shown in Fig. 7a, b, AOS inhibited the tumor size and growth rate of DU145 cells in vivo. Accordingly, tumor weights and volumes of the control group increased compared to AOS treatment groups (Fig. 7c, d). Furthermore, the ST6Gal-1 overexpressing group counteracted the AOS-induced inhibition of tumor growth in vivo. Similarly, the weight loss was prevented by ST6Gal-1 overexpression. To further investigate whether the Hippo/YAP pathway was involved in the suppression of tumor growth by AOS in vivo, the expression of related proteins was evaluated in tumor tissues by western blot. As shown in Fig. 7f, g, the expression levels of Hippo signaling molecules had changed compared to those of control cells. Interestingly, as shown in Fig. 7e, IHC analysis showed that AOS resulted in an activation of the Hippo/YAP pathway. Reintroduction of ST6Gal-1 in AOS-medication DU145 


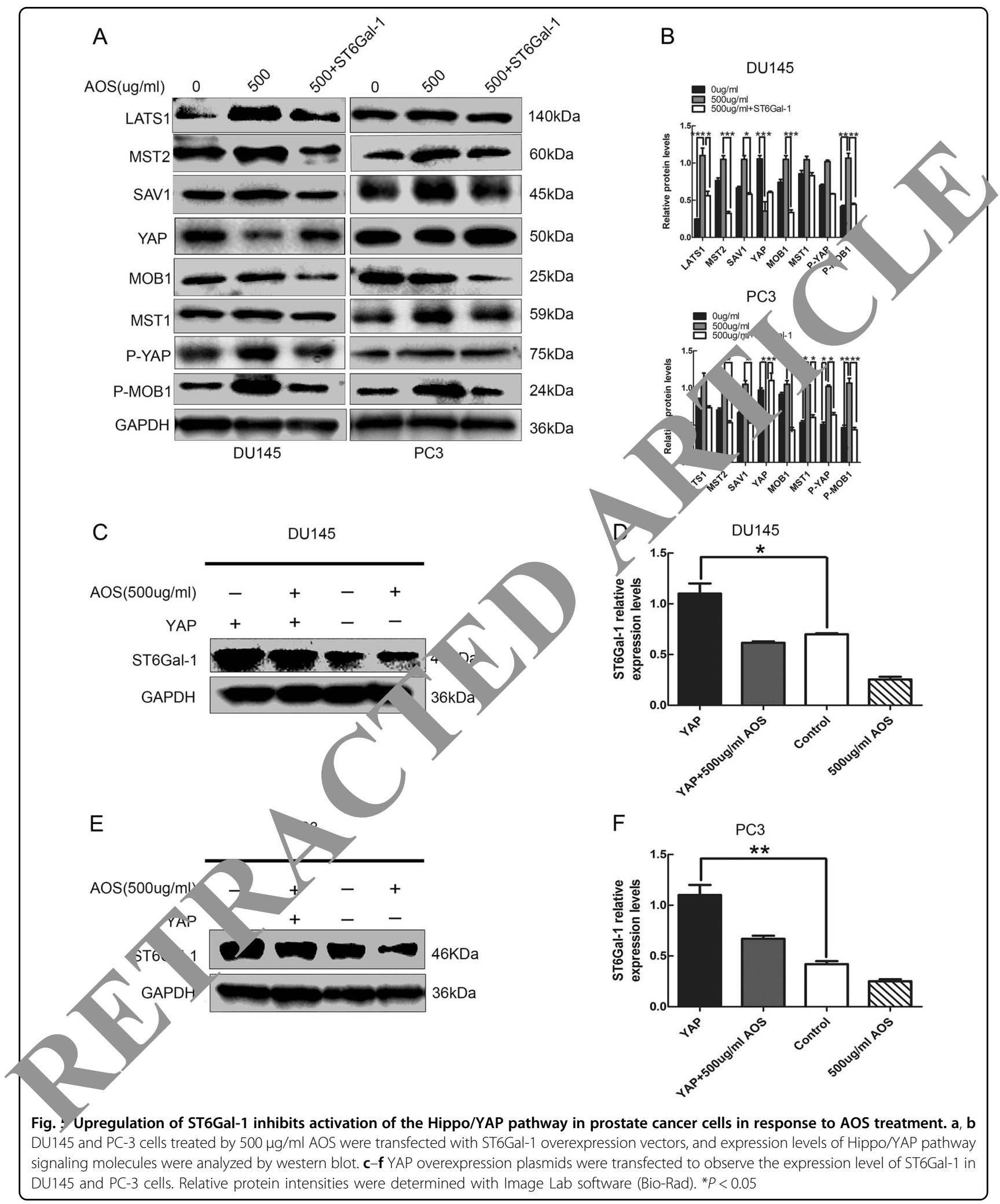

cells rescued the expression of ST6Gal-1 and Hippo signaling-related proteins at both the protein and tissue levels, respectively (Fig. 7e-g). Therefore, these findings indicate that AOS treatment suppressed tumor evolvement in prostate cancer cells through the Hippo/YAP signaling pathway in vivo. 


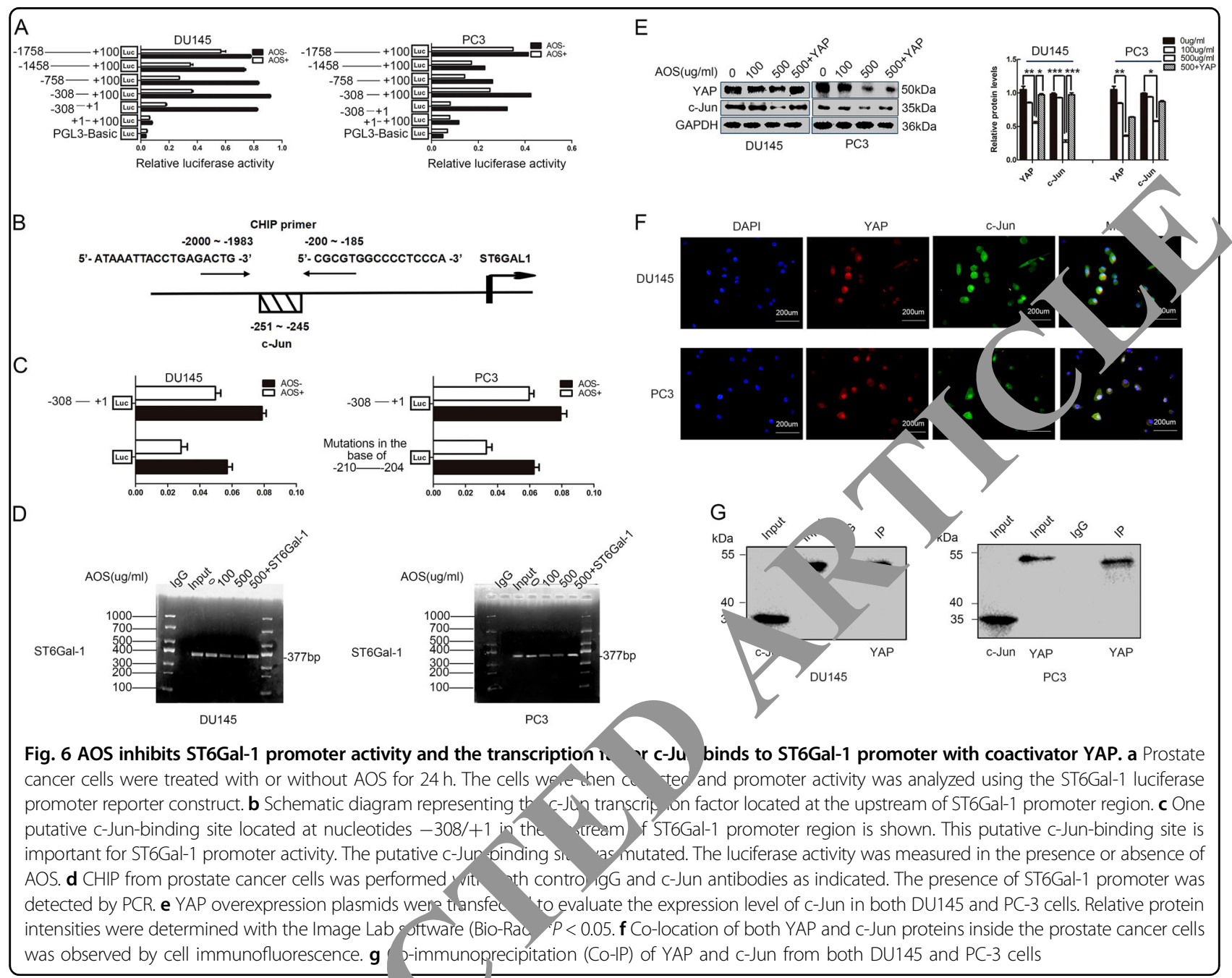

\section{Materials and methods}

\section{Alginate oligosaccharide TS)}

AOS was provided $\mathrm{H}, \sigma$ Yin from the Dalian Institute of Chemical hysi Chinese Academy of Sciences. AOS is a ma plant agomer that is obtained by enzymatic hy (roly of sodium alginate and consists of mannuronic acid ( $N_{1}$, guluronic acid $(G)$, or a heterozygous on ant of both. The chemical structure of AOS is shown is rig. 1 a.

\section{c ilinend cell culture}

$\mathrm{H}_{4}$ an prostate cancer DU145 and PC-3 cells were purchased from the Cell Bank of the Shanghai Life Science Institution, Chinese Academy of Sciences (Shanghai, China). Cells were cultured in RPMI-1640 medium supplied with $10 \%$ fetal bovine serum in a humidified incubator with $5 \% \mathrm{CO}_{2}$ and maintained at $37^{\circ} \mathrm{C}$. Both cell lines used in this study were authenticated by short tandem repeat (STR) profiling (by Shanghai Biowing Applied Biotechnology).
Cell survival assays by cell counting kit-8

Cell viability was determined using the Cell Counting Kit-8 (CCK-8) assay. Prostate cancer cells were cultured in 96-well plates at a density of 4000 cells per well and treated with a series of different doses of AOS for 24, 48, 72 , and $96 \mathrm{~h}$. Then, the AOS-containing medium was removed, CCK- 8 solution was diluted with RPIM 1640 medium (at a dilution of 1:10) and $110 \mu \mathrm{l}$ of system reagent was added to each well. Cells were incubated for $2 \mathrm{~h}$ and the absorbance at $450 \mathrm{~nm}$ was measured with a microplate reader (Thermo Fisher Scientific, USA).

\section{Colony-formation assay}

DU145 and PC-3 cells at the logarithmic growth phase were digested into a single-cell suspension with a trypsinEDTA (Gibco) solution, and then seeded into six-well culture plates (Corning, NY, USA) at a density of 2000 cells per well. After adherence, cells were treated with $\operatorname{AOS}(0,100$, and $500 \mu \mathrm{g} / \mathrm{ml})$ for $24 \mathrm{~h}$. Subsequently, a further group overexpressed ST6Gal-1 after treatment 


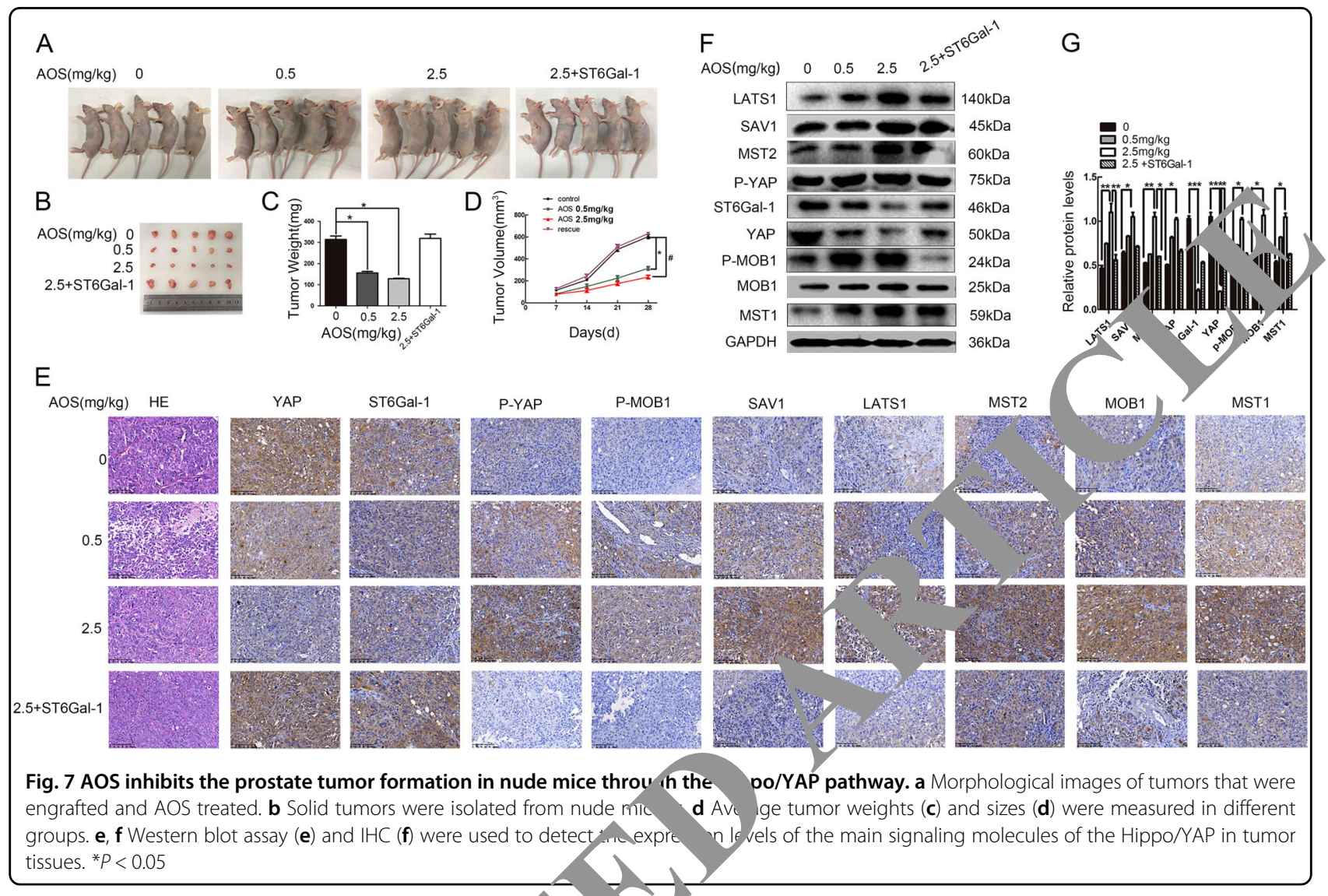

with $500 \mu \mathrm{g} / \mathrm{ml}$ AOS. After the AOS-contaning edium was removed and replaced with fresh nedium, cell, were incubated at $37^{\circ} \mathrm{C}$ with $5 \% \mathrm{CO}_{2}$ for $4 \mathrm{~d}$. The surviving cells were fixed with $4 \%$ paraformal vde nd stained with $0.1 \%$ crystal violet, and $t$ n the prates were photographed. The total number if y ues (50 cells per colony) was counted by $\mathrm{g}$ the software Image J.

\section{Wound-healing as Ay}

Cells were se. $d$ in six ell plates at a density of $5 \times$ $10^{5}$ cells per vell. hen cells had grown more than $90 \%$ confluence, the cell $\mathrm{n}$, onolayer was wounded with a $10 \mu \mathrm{l}$ sterile ${ }_{P}$ tt tip ensuring that all wounds had the same width $^{\text {th }}$ at boginning. The grouping of cells was as escr ed ab ve. Then, the culture medium was removed a. pran were washed three times using PBS. Finally, cells hat had migrated to the wounded area were observed using a microscope (Olympus, CA) and images were analyzed to determine the percentage of wound closure.

\section{Transwell migration and invasion assay}

The Costar Transwell System (8- $\mu \mathrm{m}$ pore size polycarbonate membrane, $6.5-\mathrm{mm}$ diameter, Corning, USA) was used to evaluate both cell migration and invasion.
Both DU145 and PC-3 were divided into four groups (0, $100,500,500+$ ST6) and were resuspended in $200 \mu \mathrm{l}$ serum-free RPMI-1640 medium at a density of $3 \times 10^{4}$ per well. These were added into the upper chambers and $500 \mu \mathrm{l}$ complete medium was added to the lower chambers. Then, cells were allowed to migrate for $24 \mathrm{~h}$, at which point cells on the top of the membrane were washed with PBS and removed via cotton swab. Membranes were fixed with $4 \%$ paraformaldehyde and stained with $0.1 \%$ crystal violet. Images of the membranes were obtained, counted in three non-overlapping fields, and photographed. In addition, cells were counted three times with a random approach by Image-Pro Plus 6.0 software. Similar to the above-mentioned experiment, for the invasion assay, the upper chambers were coated with $40 \mu \mathrm{l}$ Matrigel (diluted 1:8). As soon as the Matrigel solidified 30 min later, treated DU145 and PC-3 cells were seeded in the upper chambers and cultured for $24 \mathrm{~h}$.

\section{Cell cycle analysis}

Cells were fixed in $70 \%$ cold ethanol overnight at $-20^{\circ} \mathrm{C}$, washed, and then PBS was added to the suspended cells. Subsequently, cells were stained by adding propidium iodide $(50 \mu \mathrm{g} / \mathrm{ml})$ combined with RNase A $(50 \mu \mathrm{g} / \mathrm{ml})$ and this mixture was then incubated for $1 \mathrm{~h}$ at 
$37^{\circ} \mathrm{C}$. The cell cycle distribution of DU145 and PC-3 was analyzed by flow cytometer (BD Biosciences). At least $10^{6}$ cells were acquired per sample.

\section{Flow cytometry analysis for apoptosis}

In prostate cancer cells, AOS-induced apoptosis was measured by flow cytometry. In addition, the Annexin VFITC/PI apoptosis detection kit (Dojindo Laboratories, JAPAN) was used to analyze the apoptosis rate. At least $1 \times 10^{6}$ DU145 and PC-3 cells were treated with AOS (0, $100,500 \mu \mathrm{g} / \mathrm{ml}$, and $500 \mu \mathrm{g} / \mathrm{ml}+\mathrm{ST} 6)$ for $24 \mathrm{~h}$, then collected by centrifugation at $900 \times g$ for $3 \mathrm{~min}$, and washed with cold PBS three times. $1 \times 10^{6}$ cells were resuspended in $500 \mu \mathrm{l}$ Annexin $\mathrm{V}$ Binding buffer containing $5 \mu \mathrm{l}$ Annexin V-FITC and PI solutions. Next, cells were incubated at room temperature for $15 \mathrm{~min}$ in darkness. Finally, cells were analyzed by flow cytometry (BD Biosciences) within $1 \mathrm{~h}$.

\section{Lectin blot analysis}

Proteins extracted from cell lysis buffer, containing $30 \mu \mathrm{g}$ of protein, were exposed to $10 \%$ sodiumdodecyl sulfatepolyacrylamide gel electrophoresis (SDS-PAGE). One of the resulting gels was stained with Coomassie Brilliant Blue (CBB) while the other gel was transferred to a PVDr membrane for subsequent experiments. The memb ante was blocked in $5 \%$ skim milk for $3 \mathrm{~h}$ at room temp tu ? and then incubated with biotin-labeled SNA (1:2 ?, Vector) for $1 \mathrm{~h}$. Next, the PVDF membrane s wash with Tris-buffered saline, containing Tween 20 H 7.4) and incubated with diluted horseradist peroxidase, $1 R P$ )labeled streptavidin (1:8000, ZSGB-B Q) for 1 h at room temperature. Blots were visualized by hanc d chemiluminescence (ECL) kit (Advanst Menlo rark, CA, USA).

\section{Immunohistochemical ar is (It C)}

Tissue samples w o fo oy ernight in $4 \%$ paraformaldehyde to g thain ratnm-embedded sections. The sections were or raffinizo using xylene and rehydrated using an alcon ol g. lient. The antigen was repaired with sodium cirate, and $\mathrm{tr}_{1}, \mathrm{~h}$ immersed in $3 \% \mathrm{H}_{2} \mathrm{O}_{2}$ for $10 \mathrm{~min}$ to rem e dogenous catalase. The slides were washed with-DBS a blocked with goat serum for $15 \mathrm{~min}$. Next, the se tions rere incubated overnight at $4{ }^{\circ} \mathrm{C}$ using anti5 Tar-1:70, Proteintech, 14355-1-AP), anti-LATS1 (1:8 Yroteintech, 17049-1-AP), anti-SAV1 (1:80, Abcam, ab230265), anti-MST1 (1:80, Proteintech, 22245-1-AP), anti-MST2 (1:50, ABGENT, AP7923a), anti-YAP (1:200, Cell Signaling Technology, 8418), anti-p-YAP (1:1250, Cell Signaling Technology, 13008), anti-MOB1 (1:80, Proteintech, 12790-AP-1), and anti-p-MOB1 (1:50, Cell Signaling Technology, 8699) antibodies. After washing with PBS, the PBS surrounding the tissue was wiped dry and then biotinylated secondary antibody was added. The mixture was incubated at $37^{\circ} \mathrm{C}$ for $30 \mathrm{~min}$. The sections were then treated with $\mathrm{DAB}$, counterstained with hematoxylin, dehydrated with an alcohol gradient, dewaxed with xylene, dried and sealed with a neutral gum, and observed under a microscope.

\section{Western blot analysis}

Proteins were isolated by SDS-PAGE and blotto nto a PVDF membrane. Membranes were blocked with 5\% and incubated with specific primary anc. lies, fo"lowing the same method and incubate a with eroxidaseconjugated secondary antibodies. he bands, vere visualized by an ECL kit (Advansta, I nlo Pa/k, CA, USA). Subsequently, protein grayso ana, was conducted using Gel-Pro software the to wing antibodies were used: ST6Gal-1 (1:100\%, _ teintec), 14355-1-AP), p-YAP (Ser127; 1:1000, Cell Signa. Technology, 13008), YAP (1:1000, Cell Signalı, Technology, 8418), LATS1 (1:1000, Cell Signaling ' $c$ ' $\mathrm{y}, 3477)$, MST1 (1:1000, Cell Signaling Technol 3682), SAV1 (1:1000, Cell Signaling Technolo 12301). MST2 (1:1000, Cell Signaling Technology, 39:2), Iv JB1 (1:1000, Cell Signaling Technology, 13730), p-1 MOB1 (1:1000, Cell Signaling Technology, bo. and GAPDH (1:6000, Bioworld, AP0063).

\section{ny nofluorescence and immunofluorescence co.ocalization}

Cells were fixed with $4 \%$ paraformaldehyde for $20 \mathrm{~min}$, and were then successively permeabilized and blocked with $0.1 \%$ Triton-X 100 and 2\% BSA for $20 \mathrm{~min}$. Then, cells were incubated overnight with sufficient YAP primary antibody (1:400, Invitrogen, PA1-46189). A Rhodamine (TRITC)-Conjugated Goat anti-Rabbit IgG (1:50, ZSGB-BIO, ZF-0316) was used at $37^{\circ} \mathrm{C}$ for $1 \mathrm{~h}$ in the dark, and DAPI was used to stain nuclei for $5 \mathrm{~min}$. Immunofluorescence images were obtained using a microscope (Olympus, CA). In agreement with the above-mentioned immunofluorescence colocalization experiment, the two primary antibodies YAP primary antibody (1:400, Invitrogen, PA1-46189) and rabbit anti-c-Jun (1:50, Invitrogen, MA5-15172) were simultaneously incubated. The secondary antibody of Rhodamine was incubated first, and the Fluorescein-Conjugated Goat anti-Rabbit IgG antibody was incubated second (1:50, ZSGB-BIO, ZF-0311).

\section{Reverse transcription quantitative real-time PCR (RT-qPCR)}

Total RNA was extracted from DU145 and PC-3 cells using RNAiso Plus (TaKaRa, 9108, CA). Reverse transcription was conducted from $1 \mu \mathrm{g}$ total RNA, which was used to synthesize cDNA using a PrimeScript ${ }^{\mathrm{TM}}$ RT reagent Kit with gDNA Eraser (TaKaRa, RR047A). Specific Primer sequences used for qPCR have been presented previously ${ }^{25}$. Real-time quantitative RT-PCR was performed in a $10 \mu \mathrm{l}$ reaction volume containing $1 \mu \mathrm{l}$ 
cDNA template. The reactions were performed in a TransStart Tip Green qPCR SuperMix system (Transgen, AQ141) and gene expression of the target mRNA was calculated by the $2-\Delta \Delta \mathrm{Ct}$ method. The following realtime PCR parameters were used for all qPCR reactions: initial denaturation at $94{ }^{\circ} \mathrm{C}$ for $30 \mathrm{~s}$, followed by 40 cycles of $5 \mathrm{~s}$ denaturation at $94{ }^{\circ} \mathrm{C}, 30 \mathrm{~s}$ annealing, and extension at $60^{\circ} \mathrm{C}$. Furthermore, all gene expression values were normalized to that of GAPDH in the same sample.

\section{In vivo anti-tumor activity of AOS Xenograft model}

Athymic male BALB/c nude mice aged 4-6 weeks were obtained from the Animal Experiment Center of Dalian Medical University. Approximately $1 \times 10^{7}$ cells were mixed with $100 \mu \mathrm{l}$ PBS and were then subcutaneously injected into the left side of each mouse and the number of mice is twenty. After $7 \mathrm{~d}$, the nude mice gradually developed a tumor section. At this time, the diameter and length of the tumor were measured with a Vernier caliper every week, and the tumor volume was calculated using the following formula: 1/2 (length $\times$ width ${ }^{2}$ ).

\section{Analysis of anti-tumor activity of AOS in vivo}

Next, the effect of AOS on tumor cell grow ar + proliferation in vivo was confirmed. Different oncen tions of AOS were consecutively administere $r 21 \mathrm{~d} \mathrm{~b}$ intraperitoneal injection. The doses of AOS wer lected based on the findings of our previous cudies and $\mathrm{b}$, cause AOS at these doses could inhibit D 145 and PC-3 cell proliferation. The control group was ted with PBS at an amount of $100 \mu \mathrm{l}$ per day. ' mice were euthanized when the size and weight of the ros had retained a certain level for about eeks. finally, the fresh tissue was fixed in $4 \%$ par orm idehvae for more than $24 \mathrm{~h}$. After the proces of vesting, dehydration, etc., the tissue specime as emb aded in paraffin, sliced, and stained with I\&E.

\section{Transier tra sfeition}

D 145 a $\quad$ PC-3 cells were transfected with pcDNA3.1/ T6C $1-1$ an, Lipofectamine 2000 TM (Invitrogen, CA, $\checkmark$ rmused according to the manufacturer's instruction. The recombinant pcDNA3.1/ST6Gal-I vector was constructed as previously described ${ }^{26}$. Therefore, DU145 and PC-3 cells were transiently transfected with pcDNA3.1/ST6Gal-1 plasmid to rescue the inhibition of AOS on cancer cells. After $24 \mathrm{~h}$ of transfection, the rescued cells were used for further experiments. Similarly, prostate cancer cells were transiently transfected with pcDNA3.1/YAP plasmid to verify the expression of c-Jun protein.

\section{Construction of the ST6Gal-1 promoter truncated reporter gene vector and Luciferase reporter assay}

DU145 and PC-3 cells were transiently co-transfected with $1 \mu \mathrm{g}$ ST6Gal-1 promoter region firefly luciferase reporter plasmids and $2 \mathrm{ng}$ pRL-TK luciferase (Promega Corporation, Madison, WI, USA). Lipofectamine20 0 TM (Invitrogen, CA, USA) was considered as ar internal control with or without AOS in 24-well pla the ST6Gal-1 promoter region truncation secuence is $\mathrm{s}$ in Supplementary Fig. S2. Cell extracts w prepar d $24 \mathrm{~h}$ after transfection. The luciferase activity measured using the Dual-Luciferase Repor er Assay System (Promega E1910) according to the ma factur r's protocol.

\section{Co-immunoprecipitation assay (C 'P)}

Due to the well-res og. ed funcions of ST6Gal-1 and YAP in cell growth and p feration, coupled with previous data demsnst ting the binding of the transcription factor c-Jun to a promoter, it is essential to assess the interact between proteins of YAP and c-Jun. The Pier $C_{0}$-Im nunoprecipitation Kit (Thermo Scientific, 26.49) ys used to implement the endogenous immunopre ipitation assay. According to the manutau er's instructions, cells were lysed at $4{ }^{\circ} \mathrm{C}$ in IP Lysis/ Wasi Buffer. 10-75 $\mu \mathrm{g}$ of affinity-purified c-Jun antibody od as bait protein for coupling by adjusting the volume to $200 \mu \mathrm{l}$, using sufficient ultrapure water and $20 \mathrm{X}$ Coupling Buffer to produce 1× Coupling Buffer. The antibody was immobilized onto an AminoLink Plus Coupling Resin for $2 \mathrm{~h}$ at room temperature. Subsequently, cell lysates were added to the Pierce control agarose resin and incubated at $4{ }^{\circ} \mathrm{C}$ for $30 \mathrm{~min}$ to $1 \mathrm{~h}$. Then, the proteins with the above AminoLink Plus Coupling Resin were immunoprecipitated at $4{ }^{\circ} \mathrm{C}$ overnight, followed by two washes with Elution Buffer. Then, the resin-containing bead-antibody complex and protein lysate were suspended. The proteins in the supernatant were separated from the resin by centrifugation at $1000 \mathrm{~g}$ for $3 \mathrm{~min}$, followed by three washes with Elution Buffer. Finally, YAP was used as prey protein and immunoprecipitation was analyzed by western blot, following previously described steps.

\section{Chromatin immunoprecipitation (CHIP) assay}

CHIP assay was conducted using the EpiQuik ${ }^{\text {tit }}$ Chromatin Immunoprecipitation Kit (Epigentek, P-2002) following the manufacturer's instructions. Briefly, at the beginning of the procedures, antibodies were bound to the assay plate. The antibodies included: $1 \mu \mathrm{l}$ of Normal Mouse IgG as negative control, $1 \mu \mathrm{l}$ of Anti-RNA Polymerase II as positive control, and 2-4 $\mu$ g of each antibody of interest. The strip wells were covered with Parafilm M and incubated at room temperature for 60-90 min. Furthermore, the cell extracts were prepared as described in 
the next steps. DU145 and PC-3 cells were added to $9 \mathrm{ml}$ fresh culture medium containing $1 \%$ formaldehyde (final concentration) and then incubated at $37^{\circ} \mathrm{C}$ for $10 \mathrm{~min}$ on a rocking platform $(50-100 \mathrm{rpm})$. The fixation reaction was quenched by adding glycine; then, the DNA was sheared into small fragments by sonication, so that the length of the sheared DNA was between 200 and 1000 base pairs. Next, the required volume of the supernatant was diluted with CHIP Dilution Buffer and transferred to a new $1.5 \mathrm{ml}$ vial. $5 \mu \mathrm{l}$ of the diluted supernatant containing the digested chromatin was removed to a $0.5 \mathrm{ml}$ vial, labeled as "input DNA". Subsequently, the corresponding antibodies were incubated with the supernatant at room temperature $\left(22-25^{\circ} \mathrm{C}\right)$ for $60-90 \mathrm{~min}$ on an orbital shaker (50-100 rpm). Then, the DNA was purified using this kit (Epigentek, P-2002). In the immunoprecipitated DNA, the relative abundance of the DNA sequence from the ST6Gal-1 promoter region was analyzed by PCR. The following primer sequences were used: 5'-TCCTGCTCAGAACAAAGTGAC-3' (forward) and 5'-ATCTTTTGCAGCCTAGGGAT-3' (reverse).

\section{Statistical analysis}

Quantitative data were presented as mean \pm standard deviation (SD). Statistical significance was estimated by a two-tailed Student's $t$-test and analysis of varince (ANOVA). SPSS version 13.0 software was use Tl mean values of two groups were considered si onfica $^{-}$ different at $" p<0.05,{ }^{* * *} p<0.01$, and ${ }^{* * * *} p<0$

\section{Discussion}

This study described that the $r$ vel marine oligosaccharide AOS (identified from bro algaf), exhibited an anti-proliferative effect and $1 /$ ocked tne tumor progression via induction of cell cycle a. and apoptosis on human prostate cancer both in vitro and in vivo.

Abnormal prolifer on a me astasis are considered as the two leadir ${ }_{8}$ ca is or malignant cancer-related deaths ${ }^{27,28}$. It been ported that a specific concentration of $\mathrm{AOS} n$ effectively inhibit the growth and proliferation of ostey arcoma ${ }^{11}$. However, the effect of AOS 61. valìnant phenotype of prostate cancer cells has ot bu reported. The results show that the prootic 1 of gr, wth and proliferation as well as the induc$t_{1}$ or optosis are possibly vital mechanisms with whic ${ }_{\mathrm{O}} \mathrm{OS}$ achieves cancer suppression. In addition, at non-cytotoxic concentrations, AOS inhibited both the migration and invasion of DU145 and PC-3 cells (Fig. 2). These results suggest that AOS may have preventive and therapeutic effects on progression and metastasis of prostate cancer.

Aberrant sialylation has been reported to be closely associated with malignant phenotypes of cells, including invasiveness and tumorigenicity ${ }^{29}$. Overexpression of specific sialyltransferase levels is an important reason for tumorigenesis $^{30,31}$, especially ST6Gal-1 sialyltrasferse, which catalyzes $\alpha 2,6$-linked sialylation ${ }^{22}$. A previous report has shown that ST6Gal-1 played an important role in the proliferation, migration, and invasion of prostate cancer cells ${ }^{23}$. In the current study, a decrease of ST $5 \mathrm{Gal}-$ 1 was observed upon AOS treatment at mRNA protein, and glycan levels in DU145 and PC-3 cells (Fig. suggests that AOS acts on prostate cancer ce. by affecting the expression of ST6Ga- and ausing changes in SA.

ST6Gal-1-mediated $\alpha 2,6$-linked ialylation is important in cancer progression. Accumula ng evidence demonstrated that ST6Gal-1 is on axpl in colon can$\mathrm{cer}^{32,33}$, breast cancer ${ }^{34}$ iver ca $\mathrm{rr}^{35}$, cervical cancer ${ }^{36}$, and other diseases ${ }^{37} .7 \mathrm{~h}$ fore, S $\$ 0 \mathrm{Gal}-1$ has become an important diagnostic mark and therapeutic target for the detection and eatment of human cancer. In fact, changes in the portion of the gene result in the modulation of go expression regulation. This study showed ti OOS downregulated ST6Gal-1 expression at a transcrip ionar, evel in DU145 and PC-3 cells (Fig. 3). At the transcriptional level, extensive results detail the $\mathrm{CO}_{2}$ ex regulatory networks that control ST6Gal-1 $\mathrm{mRN}$ expression, such as, $\mathrm{Slug}^{38}, \mathrm{HNF}^{39}$, and $\mathrm{Sp} 1^{31}$ ns ription factors. Bioinformatics predicted that the transcription factor c-Jun binds to the ST6Gal-1 promoter region.

C-Jun is a member of the activation protein (AP1) family and is an oncogene that can be immediately and transiently expressed under the action of gonadotropins, growth factors, phorbol esters, and neurotransmitters ${ }^{40}$. It not only binds to AP1 family members, but also plays a biological role in the form of $\mathrm{AP} 1^{41}$, and can also participate in the regulation of gene transcription as a transcription factor ${ }^{42}$. Various types of stimulation such as drugs and ultraviolet irradiation can induce c-Jun activation $^{43}$. Activated c-Jun participates in various physiological processes such as proliferation and apoptosis of tumor cells by regulating target gene transcription ${ }^{44}$. A previous study showed that the interaction between KLF5 and cJun promoted Angiotensin II-induced suppression of p21 expression in vascular smooth muscle cells ${ }^{45}$. This study showed that administration of AOS significantly suppressed the expression of c-Jun, which in turn attenuated the interaction of the c-Jun transcription factor onto the promoter region of ST6Gal-1. This led to the downregulation of ST6Gal-1 mRNA expression, and subsequently inhibited DU145 and PC-3 cell proliferation, migration, and invasion.

The Hippo/YAP signaling pathway is highly conserved in mammals, with core components including MST1/2, SAV1, LATS1/2, MOB1, and YAP/TAZ. In addition, YAP is the major downstream effector of the Hippo/YAP 
signaling pathway in mammals ${ }^{46}$. Furthermore, YAP is significant in prostate cancer cells ${ }^{47}$. As a transcriptional coactivator, YAP has no DNA-binding domain and therefore cannot directly bind to DNA. Consequently, the transcriptional expression of target genes needs to be regulated by DNA-binding transcription factors such as members of the TEAD1-4 family, Smad4, RUNX1/2, p63/ p73, and ErbB4 $4^{48}$. This study showed the interaction between transcription factor YAP and the transcriptional coactivator c-Jun and then regulated the transcriptional process of the promoter in prostate cancer (Fig. 6). Moreover, it has been reported that inhibition of YAP expression was sufficient to impair migration and invasion of PC-3 cancer cells ${ }^{49}$. Here, we showed that AOS activated the Hippo/YAP pathway in both DU145 and PC-3 cells (Fig. 4). The total YAP level decreased and lower nucleus YAP levels were a final result of alleviated nucleus location due to YAP phosphorylation (Ser127) and the decrease of total YAP level. However, it to be further elucidated whether AOS (as a small molecule) is dissolved by cells and whether there is any difference in the antitumor effect between AOS mixture and AOS monomer. Furthermore, whether AOS enters cancer cells to exert tumor suppressive effects, and what upstream signals and receptors of AOS act on the Hippo signaling pathway also remains to be further elucidated. Moreover, the reli nice on DU145 and PC3 cells, limits the potential trans- on 1 relevance of the results. Both cell lines represer the null subtype of metastatic prostate cancer. $\mathrm{T}_{1}$ issue wi be further studied.

In summary, we have provided the first eviden, that AOS inhibits prostate cancer cell prol eration yia changes in SA and by affecting the expre of ST6Gal-1. Moreover, these effects manil ted at a non-cytotoxic concentration of AOS and attenu, the proliferation, migration, and invasion huma prostate cancer cells through suppression $f$ th. Hipyo/YAP/c-Jun pathway. These findings pro ide . "ohts regarding the mechanisms of AOS-mediat anti-pro eration action. Furthermore, the problem of tox ide effects on normal cells cannot be ignored; nerefore, $t$, development of the application potentic of $\mathrm{OS}$ to increase its selective efficacy against tumar celt a very worthwhile research topic.

\section{0 \\ Ackı. 'edgements}

This wo $\mathrm{n}$ was supported by the National Natural Science Foundation of China (31470799), the Natural Science Foundation of Liaoning Province

(20170540288), the Special Fund of Dalian city for Distinguished Young Scholars (2017RJ07), and the National Key R\&D Program of China (2017YF0200900). And this work was supported by Liaoning Provincial Program for Top Discipline of Basic Medical Sciences. None of these funding sources had any role in writing the manuscript nor in the decision to submit for publication. The authors attest that they have not been paid to write this article by a company or any other agency. The alginate oligosaccharide was provided by Heng Yin of the Dalian Institute of Chemical Physics, Chinese Academy of Sciences.

\section{Author details}

${ }^{1}$ Department of Biochemistry and Molecular Biology, College of Basic Medical Sciences, Institute of Glycobiology, Dalian Medical University, Dalian, Liaoning, China. ${ }^{2}$ Department of Pathology, College of Basic Medical Sciences, Dalian Medical University, Dalian, Liaoning, China. ${ }^{3}$ Liaoning Provincial Key Laboratory of Carbohydrates, Dalian Institute of Chemical Physics, Chinese Academy of Science, Dalian, China

\section{Authors' contributions}

H.Y. performed, analyzed data, and wrote the manuscript. H.Y. ar designed the experiments. Y.H. provided alginate oligosaccharide. provided the tissue slices. All authors were involved in riting this pap and approved the submission and publication. In Fig. 1, H.Y. erated th data. Y. $\mathrm{H}$. provided the structure of alginate oligosacchar: In Fls $\mathrm{H}_{\text {.Y }}$ generated the data. Z.L. supported the data analysis. In Fir $3.3,4,5$, and 6 , . . assembled the data. In Fig. 7, Y.X. generated the immun histochemistry data.

\section{Data availability}

Data that supports this research p'sorvation been shown in the article and Supplementary Information.

\section{Conflict of interest}

The authors declare that have no, conflict of interest.

\section{Ethics approval}

All animal cre and exper ntal procedures were performed in accordance with a proto roved by the Institutional Animal Care and Ethics Committee of Dal an dical University (AEE18033). In addition, all animal experiments in ne present study were consistent with the National Institutes of $H$ ealth guide $y$ the care and use of laboratory animals.

hlish er's note

Sp yer Nature remains neutral with regard to jurisdictional claims in ublished maps and institutional affiliations.

Supplementary Information accompanies this paper at (https://doi.org/ 10.1038/s41419-019-1560-y).

Received: 6 January 2019 Revised: 23 March 2019 Accepted: 26 March 2019 Published online: 10 May 2019

\section{References}

1. Zaorsky, N. G., Raj, G. V., Trabulsi, E. J., Lin, J. \& Den, R. B. The dilemma of a rising prostate-specific antigen level after local therapy: what are our options? Semin. Oncol. 40, 322-336 (2013)

2. Valerio, M., Emberton, M., Eggener, S. E. \& Ahmed, H. U. The challenging landscape of medical device approval in localized prostate cancer. Nat. Rev. Urol. 108, 377-403 (2015)

3. Bhandari, M. S., Petrylak, D. P. \& Hussain, M. Clinical trials in metastatic prostate cancer-has there been real progress in the past decade? Eur. J. Cancer 41, 941-953 (2005).

4. Fong, Z. V. \& Tanabe, K. K. The clinical management of hepatocellular carcinoma in the United States, Europe, and Asia: a comprehensive and evidencebased comparison and review. Cancer 120, 2824-2838 (2015).

5. Guo, J. J. et al. Alginate oligosaccharide prevents acute doxorubicin cardiotoxicity by suppressing oxidative stress and endoplasmic reticulum-mediated apoptosis. Marine Drugs 14, 231 (2016).

6. Yang., Y. et al. Alginate oligosaccharide indirectly affects toll-like receptor signaling via the inhibition of microRNA-29b in aneurysm patients after endovascular aortic repair. Drug Des. Dev. Ther. 11, 2565-2579 (2017).

7. Tusi, S. K., Khalaj, L., Ashabi, G., Kiaei, M. \& Khodagholi, F. Alginate oligosaccharide protects against endoplasmic reticulum- and mitochondrialmediated apoptotic cell death and oxidative stress. Biomaterials $\mathbf{3 2}$, 5438-5458 (2011)

8. Guo, J. J. et al. Alginate oligosaccharide alleviates myocardial reperfusion injury by inhibiting nitrative and oxidative stress and endoplasmic reticulum stressmediated apoptosis. Drug Des. Dev. Ther. 11, 2387-2397 (2017). 
9. Pritchard, M. F. et al. A low molecular weight alginate oligosaccharide disrupts pseudomonal microcolony formation and enhances antibiotic effectiveness. Antimicrob. Agents Chemother. 61, AAC.00762-17 (2017).

10. Zhou, J. et al. The marine-derived oligosaccharide sulfate MS80, a novel TGF$\beta 1$ inhibitor, reverses TGF- $\beta 1$-induced epithelial-mesenchymal transition and suppresses tumor metastasis. J. Pharmacol. Exp. Ther. 359, 54-61 (2016).

11. Chen, J. et al. Alginate oligosaccharide DP5 exhibits antitumor effects in osteosarcoma patients following surgery. Front. Pharmacol. 8, 623 (2017).

12. Fischer, C. et al. Panobinostat reduces hypoxia-induced cisplatin resistance of non-small cell lung carcinoma cells via HIF-1alpha destabilization. Eur. J. Cancer 14, 4 (2015).

13. Kailemia, M. J., Park, D. \& Lebrilla, C. B. Glycans and glycoproteins as specific biomarkers for cancer. Anal. Bioanal. Chem. 409, 395-410 (2016).

14. Christiansen, M. N. et al. Cell surface protein glycosylation in cancer. Proteomics 14, 525-546 (2014).

15. Crespo, H. J., Lau, J. T. \& Videira, P. A. Dendritic cells: a spot on sialic acid. Front. Immunol. 4, 491 (2013).

16. Suzuki, O., Abe, M. \& Hashimoto, Y. Sialylation by $\beta$-galactoside a-2,6-sialyltransferase and $\mathrm{N}$-glycans regulate cell adhesion and invasion in human anaplastic large cell lymphoma. Int. J. Oncol. 46, 973-980 (2015).

17. Ranjan, A. \& Kalraiya, R. D. a 2,6 Sialylation associated with increased $\beta 1,6-$ branched $\mathrm{N}$-oligosaccharides influences cellular adhesion and invasion. J. Biosci. 38, 867-876 (2013).

18. Badr, H. A. et al. Harnessing cancer cell metabolism for theranostic applications using metabolic glycoengineering of sialic acid in breast cancer as a pioneering example. Biomaterials 116, 158-173 (2017).

19. Swindall, A. F. et al. ST6Gal-I protein expression is upregulated in human epithelial tumors and correlates with stem cell markers in normal tissues and colon cancer cell lines. Cancer Res. 73, 1368-1378 (2013).

20. Schultz, M. J. et al. The tumor-associated glycosyltransferase ST6Gal-I regulates stem cell transcription factors and confers a cancer stem cell phenotype. Cancer Res. 76, 3978-3988 (2016).

21. Antony, P. et al. Epigenetic inactivation of ST6GAL1 in human bladder cancer. BMC Cancer 14, 901 (2014).

22. Zhao, Y. et al. a2,6-Sialylation mediates hepatocellular carcinoma growth in vitro and in vivo by targeting the Wnt/ $\beta$-catenin pathway. Oncos cis. e343 (2017).

23. Wei, A. et al. ST6Gal-I overexpression facilitates prostate can rogression the PI3K/Akt/GSK-3ß/ß-catenin signaling pathway. Oncot get. 374-65388 (2016).

24. Su, X. et al. TAp63 suppresses mammary tumorig nesis through reg, ration of the Hippo pathway. Oncogene 36, 2377-2393 ( 17).

25. Yuan, Q. et al. Modification of a2,6-sialylation $m$ iates the ir vasiveness and tumorigenicity of non-small cell lung cancer ce. vitr. and in vivo via Notch1/Hes1/MMPs pathway. Int. J. Cal 143, 2319-2330 (2018).

26. Chen, $X$. et al. ST6Gal-I modulates doc Ptan ritivity in human hepatocarcinoma cells via the p38 MAPK raspase pathway. Oncotarget 7, 51955-51964 (2018).

27. Bao, Y. W., Hua, X. W., X. XN/1.F. J. Platinum-doped carbon nanoparticles inhibit canor ce, gratım under mild laser irradiation: multiorganelle-targeted bhotothern herapy. Biomaterials 183, 30-42 (2018).

28. Wu, G., Liu, J., Yu, Wu, X. \& Yà, X. MicroRNA-184 inhibits cell proliferation and metastasis in hui colorectal cancer by directly targeting IGF-1R. Oncol. Lett. 14 o $21 \mathrm{~T}$ (2017).

29. Zhao et o Modification of sialylation mediates the invasive properties and chemo iviry of human hepatocellular carcinoma. Mol. Cell. Proteomics 13,

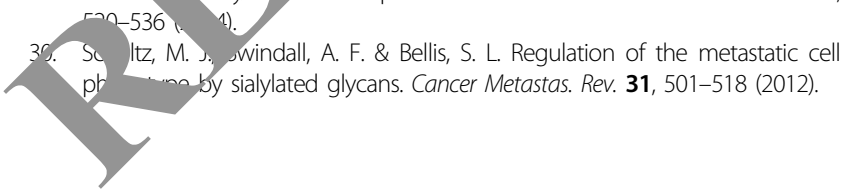

31. Lu, J. et al. $\beta$-Galactoside a2,6-sialyltranferase 1 promotes transforming growth factor- $\beta$-mediated epithelial-mesenchymal transition. J. Biol. Chem. 289, 34627-34641 (2014)

32. Qian, L. et al. a 2,6-linked sialic acid serves as a high-affinity receptor for cancer oncolytic virotherapy with Newcastle disease virus. J. Cancer Res. Clin. Oncol. 143, 2171-2181 (2017).

33. Dall'Olio, F. et al. Beta-galactoside alpha 2,6 sialyltransferase in human colon cancer: contribution of multiple transcripts to regulation cazyme activity and reactivity with Sambucus nigra agglutinin. Int. J. ancer $\mathbf{8 8}, 58$ (2000).

34. dos-Santos, P. B. et al. Eduardo Isidoro Carneiro Beltrão. Lectin histo mistry reveals SNA as a prognostic carbohydrate-depende th probe for in sive ductal carcinoma of the breast: a clinicopatholog and imn unohistochemical auxiliary tool. Int. J. Clin. Exp. Pathol. 7 37-2s 2015

35. Yu, S. et al. Caveolin-1 up-regulates inter in a2,6-sialyla a to promote integrin a5 $\beta 1$-dependent hepatocarcinoma ell adhesion FEBS Lett. 587, 782 (2013).

36. Lópezmorales, D., Reyesleyva, J., Szan 'ópez, Increased expression of sialic as in a biopsies with squamous intraepithelial lesions. Diagn. Patho 5, 1-5 (20)

37. Kaburagi, T., Kizuka, Y., Kit Uur \& Taniguceni, N. The inhibitory role of a2,6 sialylation in adipogenesis. J. Bior. om. 292, 2278 (2017).

38. Schultz, M. J. et tract 332 he tumor associated sialyltransferase ST6Gal-I promo 's a c icer stem cell phenotype and upregulates stemrelated transcrip fa icer Res. 76, 3978-3988 (2017).

39. $\mathrm{Xu}, \mathrm{L}$. et al. Transc nal regulation of human beta-galactoside alpha2,6sialyltrai crase (hST6G, gene in colon adenocarcinoma cell line. Biochem. Biophys. om 307, 1070-1074 (2003).

40. Singh, V. R, Katta,, . \& Kumar, S. WD-repeat protein WDR13 is a novel transcriptional egulator of c-Jun and modulates intestinal homeostasis in mice. MMC Cancer i7, 148 (2017).

41. kur, N. et al. TGF $\beta$-induced invasion of prostate cancer cells is promoted by c- 1-dependent transcriptional activation of Snail1. Cell Cycle 13, 2400-2414 $20,4)$.

4. Lukey, M. J., Kai, S. G., Erickson, J. W., Wilson, K. F. \& Cerione, R. A. J. N. C. The oncogenic transcription factor $\mathrm{C}-J u n$ regulates glutaminase expression and sensitizes cells to glutaminase-targeted therapy. Nat. Commun. 7, 11321 (2016).

43. Pfundt, R. et al. In situ demonstration of phosphorylated c-jun and p38 MAP kinase in epidermal keratinocytes following ultraviolet B irradiation of human skin. J. Pathol. 193, 248-255 (2001).

44. Krestnikova, N., Stulpinas, A., Imbrasaite, A., Sinkeviciute, G. \& Kalvelyte, A. V. JNK implication in adipocyte-like cell death induced by chemotherapeutic drug cisplatin. J. Toxicol. Sci. 40, 21-32 (2015).

45. He, M., Han, M., Zheng, B., Shu, Y. N. \& Wen, J. K. J. J. O. B. Angiotensin ॥ stimulates KLF5 phosphorylation and its interaction with c-Jun leading to suppression of p21 expression in vascular smooth muscle cells. J. Biochem. 146, 683-691 (2009).

46. Zhang, N. et al. The Merlin/NF2 tumor suppressor functions through the YAP oncoprotein to regulate tissue homeostasis in mammals. Dev. Cell 19, 27-38 (2010).

47. Zhang, L. et al. The hippo pathway effector YAP regulates motility, invasion, and castration-resistant growth of prostate cancer cells. Mol. Cell. Biol. 35, 1350 (2015).

48. Mo, J. S., Park, H. W. \& Guan, K. L. The Hippo signaling pathway in stem cell biology and cancer. EMBO Rep. 15, 642-656 (2014).

49. Collak, F. K., Demir, U., Ozkanli, S., Kurum, E. \& Zerk, P. E. Increased expression of YAP1 in prostate cancer correlates with extraprostatic extension. Cancer Biol. Med. 14, 405-413 (2017) 